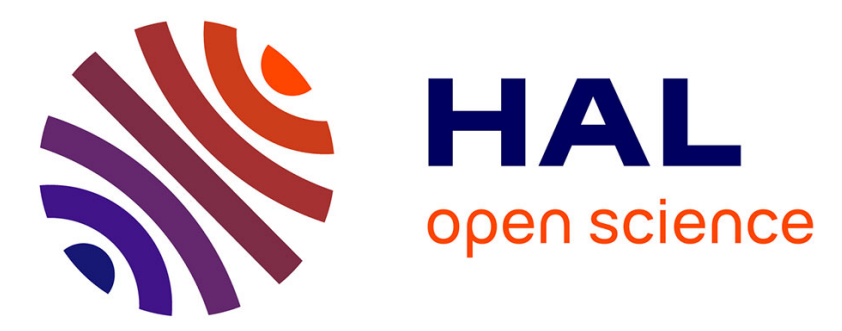

\title{
Are pheasants attracted or repelled by roads? A test of a crucial assumption for transect censuses
}

Emilia Venturato, Paolo Cavallini, Francesco Dessì-Fulgheri

\section{To cite this version:}

Emilia Venturato, Paolo Cavallini, Francesco Dessì-Fulgheri. Are pheasants attracted or repelled by roads? A test of a crucial assumption for transect censuses. European Journal of Wildlife Research, 2009, 56 (3), pp.233-237. 10.1007/s10344-009-0309-9 . hal-00535243

\section{HAL Id: hal-00535243 \\ https://hal.science/hal-00535243}

Submitted on 11 Nov 2010

HAL is a multi-disciplinary open access archive for the deposit and dissemination of scientific research documents, whether they are published or not. The documents may come from teaching and research institutions in France or abroad, or from public or private research centers.
L'archive ouverte pluridisciplinaire HAL, est destinée au dépôt et à la diffusion de documents scientifiques de niveau recherche, publiés ou non, émanant des établissements d'enseignement et de recherche français ou étrangers, des laboratoires publics ou privés. 


\title{
Are pheasants attracted or repelled by roads? A test of a crucial assumption for transect censuses
}

\author{
Emilia Venturato • Paolo Cavallini • \\ Francesco Dessì-Fulgheri
}

Received: 25 November 2008 /Revised: 29 June 2009/Accepted: 27 July 2009 / Published online: 20 August 2009

(C) Springer-Verlag 2009

\begin{abstract}
Censuses are widely used to monitor populations. One of the most interesting modern techniques is distance sampling, which depends on some crucial assumptions, including the random distribution of animals with respect to transect lines, which are often asphalt and gravel roads. We tested the assumption of a random distribution of animals with respect to roads for females of ring-necked pheasants (Phasianus colchicus). Roads can be used to census pheasants using distance sampling, without significant bias because pheasants are randomly distributed with respect to roads. Our method is easy to apply to other field conditions where radio tracking data are available and can be used to test the assumption in other studies and/or with different species.
\end{abstract}

Keywords Distance sampling · Censuses · Pheasant .

Road · Transect

Communicated by C. Gortázar

E. Venturato $(\bowtie)$

Dipartimento di Biologia Evoluzionistica 'Leo Pardi', Università di Firenze,

via Romana 17/19,

50125 Florence, Italy

e-mail: venturato@faunalia.it

P. Cavallini

Faunalia,

piazza Garibaldi 5,

56025 Pontedera, PI, Italy

e-mail: cavallini@faunalia.it

F. Dessì-Fulgheri

Dipartimento di Biologia Evoluzionistica 'Leo Pardi',

Università di Firenze and Centro Interuniversitario di Ricerca

sulla Selvaggina e sui Miglioramenti Ambientali a fini Faunistici,

via Romana $17 / 19$,

50125 Florence, Italy

e-mail: dessi@unifi.it

\section{Introduction}

Censuses are a common and widely used technique in wildlife biology to monitor populations. A variety of different methods are currently used, in relation to species, habitats, aims of the study, and budget. One of the most interesting modern techniques is based on distance sampling (Buckland 2001). It has a number of interesting properties, including the direct estimate of confidence intervals (Norvell et al. 2003), and can improve estimates of population sizes (Newson et al. 2008). Correct estimates, however, are dependent on a number of crucial assumptions: (1) animals on the line or point must be detected with certainty; (2) animals must be detected at their initial location; (3) measurements must be exact, and (4) transects must be placed randomly with respect to the distribution of animals in the environment. While the first two assumptions can be met in a variety of field conditions with a careful execution of censuses, the third one is often infeasible, especially when censuses are carried out from a vehicle; this happens often to cover wider areas, to reduce the need for manpower, and for safety concerns. In this case, roads and field paths are often used instead of random, linear transects. This can give incorrect results if: (1) animals are attracted by roads (e.g., because of better cover on the roadsides) or repelled by them (e.g., because of disturbance) and if (2) home ranges of animals are not placed randomly with respect to roads (Buckland 2001). This assumption has not been, to the best of our knowledge, widely tested, in particular for Galliformes birds.

Our objective was to test the random distribution assumption of animals with respect to roads (both asphalt and gravel) using female ring-necked pheasants (Phasianus colchicus), equipped with radio transmitters to obtain a relatively unbiased sample of locations. 
Table 1 Basic statistics on size, roads, and pheasants in the two study areas

\begin{tabular}{lcc}
\hline Study area & Arno plains & Volterra hills \\
\hline Total surface $(\mathrm{ha})$ & 1,150 & 1,300 \\
Asphalt road $(\mathrm{km})$ & 17.41 & 11.91 \\
Asphalt road density $\left(\mathrm{km} / \mathrm{km}^{2}\right)$ & 1.51 & 0.86 \\
Gravel road $(\mathrm{km})$ & 27.38 & 21.75 \\
Gravel road density $\left(\mathrm{km} / \mathrm{km}^{2}\right)$ & 2.37 & 1.57 \\
Radio-marked pheasants $(n)$ & 34 & 47 \\
Density of pheasants average 2002-2007 $\left(n / \mathrm{km}^{2}\right)$ & 39.7 & 14.2 \\
Pheasant localization $(n)$ & 1,729 & 2,053 \\
\hline
\end{tabular}

\section{Materials and methods}

Two study areas (1,150 and 1,300 ha) were selected within Pisa Province (Tuscany, Central Italy). In both areas, hunting and release of pen-raised animals were not allowed. One of the two areas was in the flat Arno Valley close to Pisa; the other was in the low (up to $300 \mathrm{~m}$ a.s.1.) hills close to Volterra. The first was intensively cultivated $(99 \%$ of total surface) and had some urban areas, practically without woodlands, and with very little hedgerows. The second was also cultivated, though less intensively (77\%) and had significant wooded areas (around 20\%). The two study areas had different road densities and number of animal locations (Table 1). Roads were not placed randomly in the two areas (Figs. 1 and 2), especially in the hilly area, where they mostly followed the crest of the hills, avoiding valley bottoms. Wild pheasants were trapped using funnel traps during January and February 2005-2007 and equipped with a radio-collar that lasted until October-November. Traps were opportunistically placed in areas most suitable for capture, irrespective of roads; several trapping sites were utilized at different times, according to weather and manpower. Not all the locations were known to us; therefore, it was impossible to test the true randomness of their placement. However, an eventual nonrandomness would only have influenced the first of our tests and not the second

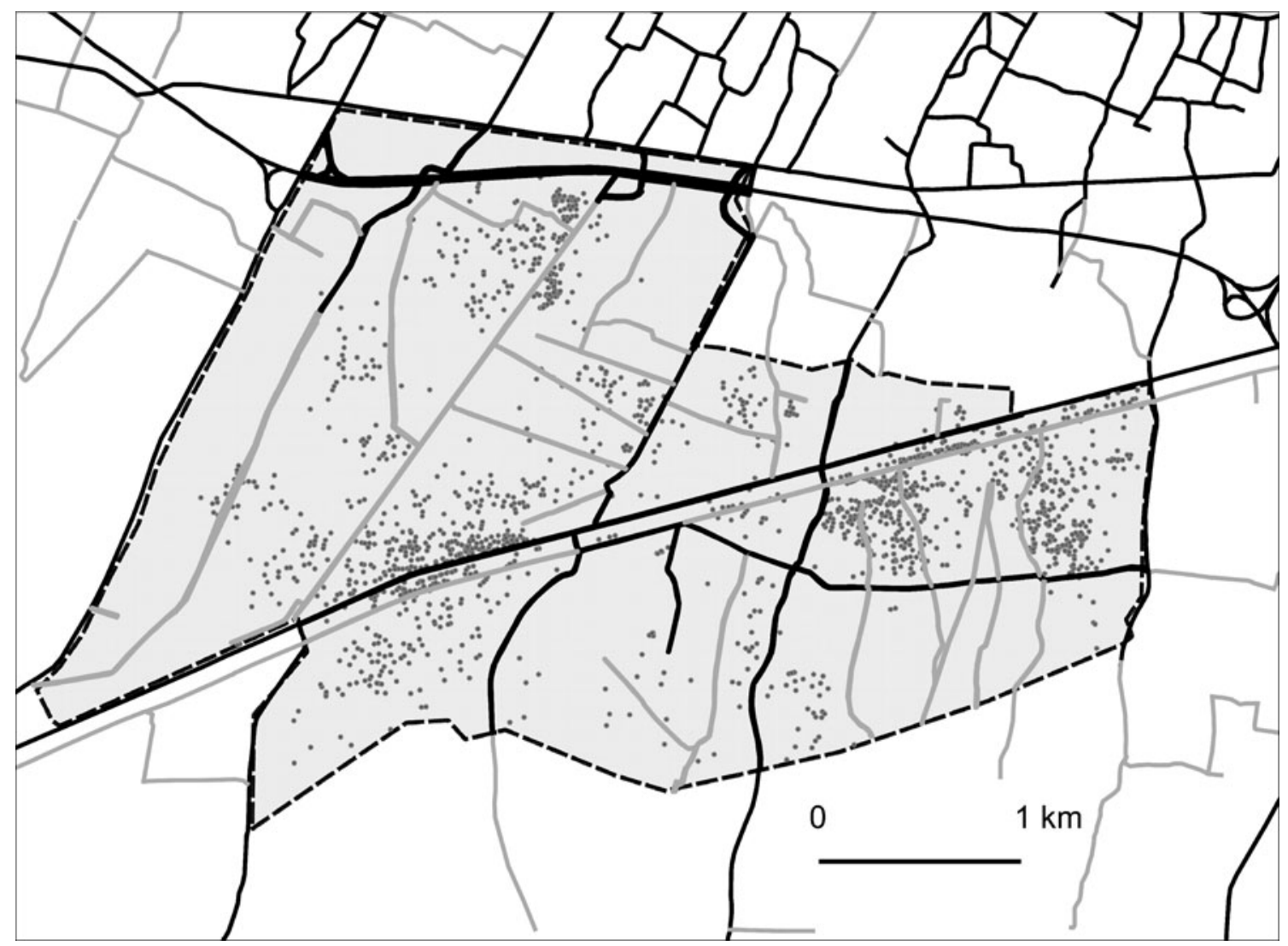

Fig. 1 Distribution of roads (asphalt road in black and gravel in gray) and pheasant locations in the study area in the plains 


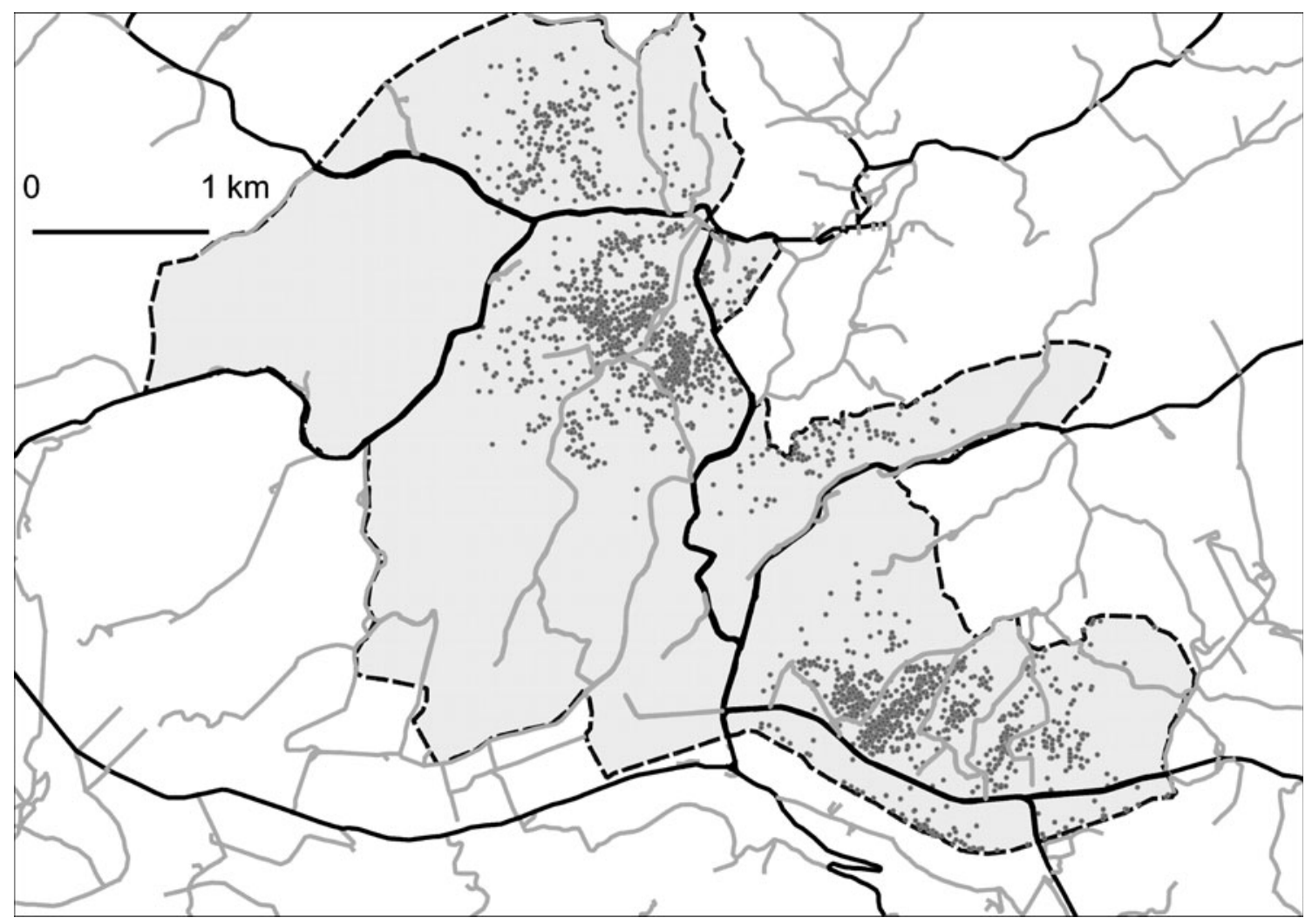

Fig. 2 Distribution of roads (asphalt road in black and gravel in gray) and pheasant locations in the study area in the hills

(centroid minimum convex polygon (MCP), see "Materials and methods"). Pheasants were released immediately after marking in the same areas where they were trapped. Average radio mass was $18.5 \mathrm{~g} \pm 3.0 \mathrm{SD}(1-3 \%$ of total body mass) and operated on the 151.001-151.999 Mhz frequency range (Venturato et al. 2009). Radio tracking was conducted by triangulation at least twice a week during daytime, and when an individual was found in the same location on two consecutive occasions, it was homed in to verify its state (dead/alive), as the transmitters did not have a mortality sensor. Standard techniques were used to determine the location of the animal (White and Garrott 1990). Two bearings were taken at very short interval (generally less than $3 \mathrm{~min}$ ) and as close as possible to $90^{\circ}$ from each other. In case of doubt, additional bearings were taken. Precision of location estimate was confirmed by frequent resights. If radio contact was lost, wider searches were conducted in the whole area and in the surroundings (in a radius of $>3 \mathrm{~km}$ ), with the help of an omnidirectional antenna mounted on the roof of a car. We continued tracking until the death of the animal or the disappearance of the radio signal.

Asphalt and gravel roads (including field paths suitable for censusing from a four-wheel-drive car) in the study areas were surveyed using a Global Positioning System receiver and plotted on a Geographic Information System.
Roads in the surroundings were plotted mainly from ortophoto maps, with additional surveying.

To mimic real observations of animals during visual censuses, we excluded locations of pheasants on their nest, dead animals, and those outside the study area. We also excluded individuals with $<10$ locations. Ten locations are obviously insufficient to determine home range size, but this is irrelevant for our purposes, as the sighting (or the location) is the unit to be tested. Locations were not independent samples but repeated measures of the same individual. We therefore calculated minimum convex polygon for every pheasant to determine an approximate home range. We generate in each range a series of random points (in equal number to radio locations for each animal) to compare the distribution of random points and pheasant location in relation to roads that could be used as census transects. Euclidean distances were then calculated from each point (either animal or random location) to the closest asphalt and gravel road. One could argue that, even if the distribution of animal locations inside home ranges was random, the ranges could be nonrandomly placed with respect to roads. To test for this, we calculated the centroids of the MCP for each individual and generated an equal number of random points in the study area. We then calculated the distance to roads both for centroids and random points. 
We used only free and open source software (Tufto and Cavallini 2005) Debian GNU/Linux operating system, PostgreSQL/PostGIS relational database, QuantumGIS, and OpenOffice.org suite. Statistical analyses have been performed using R (R Development Core Team 2008), using a single multivariate linear model (analysis of variance (ANOVA)) to test all the effects.

\section{Results}

We tagged with radio collars 101 individuals; a low number of radio locations for some individuals reduced sample size in most analyses to 81 . Sample size was maximum immediately after the captures, decreasing due to mortality and radio failure until October-November. Because of the higher density of gravel roads, both animal and random locations were significantly further from asphalt roads (animal locations, $274.7 \pm 180.7 \mathrm{~m}$; random points, $271.5 \pm$ $179.7 \mathrm{~m}$ ) than from gravel ones (animal locations, 134.2 \pm $109.4 \mathrm{~m}$; random points, $132.1 \pm 113.3 \mathrm{~m}$; Table 2). The two areas also had different distances (an effect of different road density), and the interaction between road type and study area was significant. On the other hand, distances of animal and random locations were almost identical, both from asphalt and from gravel roads (Table 2; Fig. 3).

The home ranges appeared to be placed randomly with respect to the roads: average minimum distance of the centroids of MCP from asphalt roads was $296.9 \pm 175.4 \mathrm{~m}$, whereas random points averaged $293.7 \pm 247.4 \mathrm{~m}$; for gravel roads, averages \pm SD were $122.4 \pm 98.8$ vs $149.8 \pm$ $113.4 \mathrm{~m}$. The difference between road type was significant $(F=71.6, p<0.001)$, whereas the difference between animal and random locations was not $(F=0.41, p=0.52$; Fig. 4$)$.

\section{Discussion}

Our data confirm that roads (both asphalt and gravel) can be used to census ring-necked pheasants using distance sampling without significant bias. Our results only apply to females and do not necessarily hold true for males. However, we have no reason to believe it would not, at least where males and female pheasants have similar habitat selection

Table 2 Effect of study area, road type, and location type on minimum distance to nearest road (ANOVA, with individual pheasants as a nested factor)

\begin{tabular}{llrc}
\hline Parameter & $d f$ & \multicolumn{1}{l}{$F$} & \multicolumn{1}{l}{$P$} \\
\hline Arno plain vs Volterra hills & 1 & 31.24 & $<<0.001$ \\
Asphalt vs gravel & 1 & 4358.44 & $<<0.001$ \\
Fix vs random & 1 & 1.52 & 0.22 \\
\hline
\end{tabular}

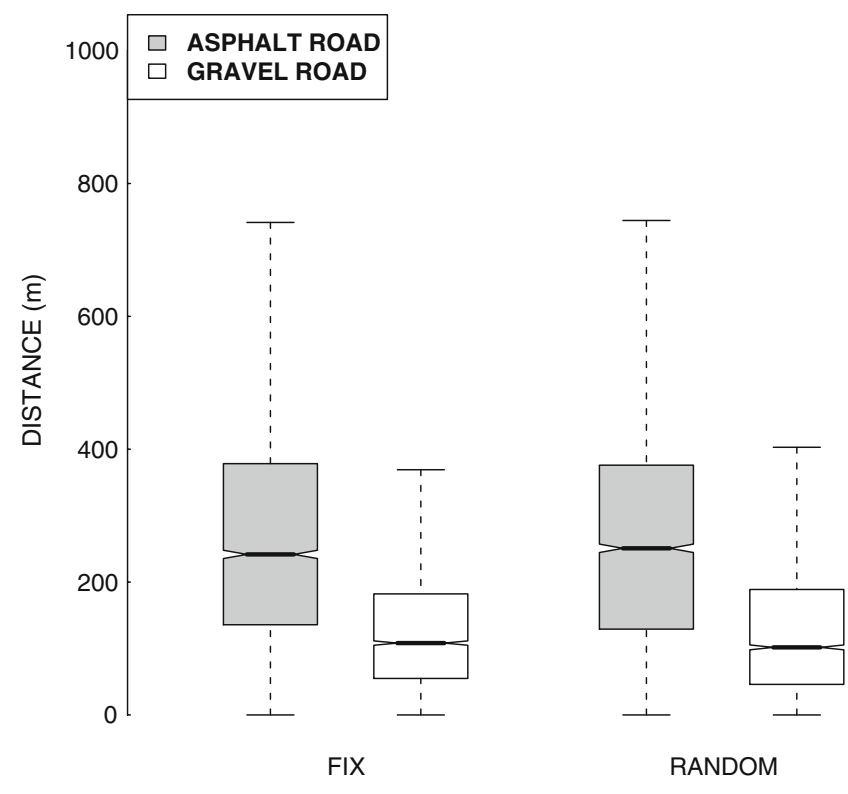

Fig. 3 Minimum euclidean distance from asphalt and gravel road to pheasant locations and random points (inside minimum convex polygon)

(Smith et al. 1999). Our two study areas are sufficiently different and results sufficiently clear cut to give some confidence about the generality to our conclusions regarding this species. Obviously, other species can behave quite differently and will require further study. However, radio tracking data are widely available for a huge variety of species, and the method we used is easy to apply to other field conditions. We therefore encourage researchers to apply the same method to other species to check the same assumptions in a variety of different situations.

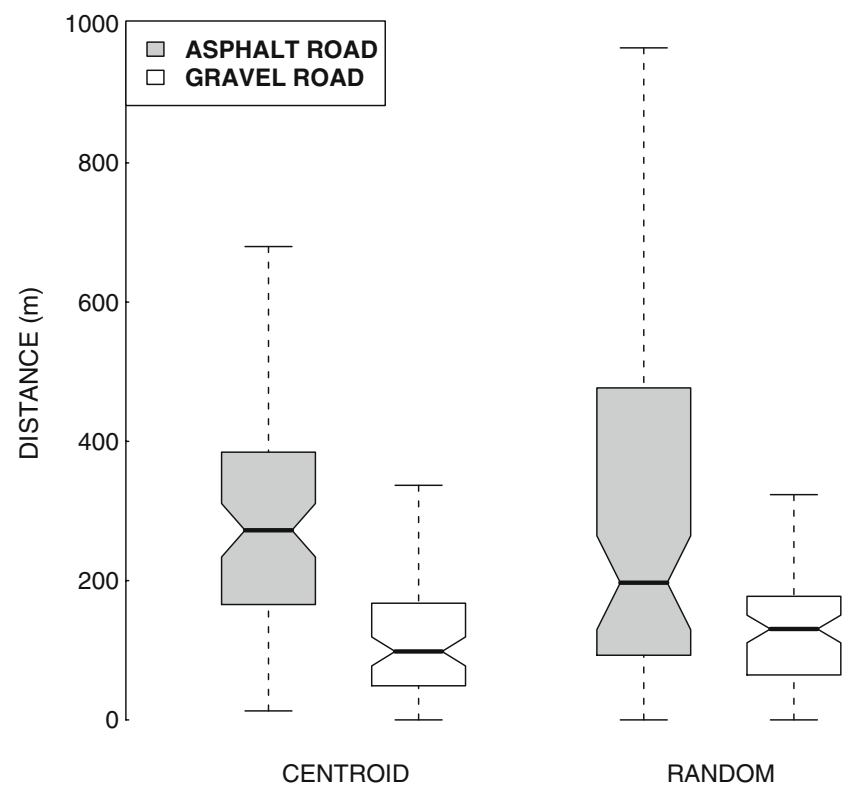

Fig. 4 Minimum euclidean distance from asphalt and gravel road to minimum convex polygon centroids and random points (inside each study area) 
Acknowledgments This study is a part of a larger project on the effects of habitat management on pheasant reproduction and density. The project has implicated the active participation of students and staff from both the University of Florence and Faunalia: Carlotta Canova, Serena Calastri, Claudia Gasparini, Claudia Fabbrizzi, Daniele Scarselli, Riccardo Petrini, and Leonardo Lami. They are all gratefully acknowledged. The project has been generously funded by the Toscana Regional Administration (Dr. Paolo Banti) and the Pisa Provincial Administration (Dr. Roberto Mazzoni della Stella); their advice and encouragement have been fundamental for the success of the project and of this study.

\section{References}

Buckland ST (2001) Introduction to distance sampling: estimating abundance of biological populations. Oxford University Press, USA

Newson SE, Evans KL, Noble DG, Greenwood JJD, Gaston KJ (2008) Use of distance sampling to improve estimates of national population sizes for common and widespread breeding birds in the UK. J Appl Ecol 45:1330-1338

Norvell RE, Howe FP, Parrish JR (2003) A seven-year comparison of relative-abundance and distance-sampling methods. The Auk 120:1013-1028

R Development Core Team (2008) R: A language and environment for statistical computing. Vienna, Austria. Available at: http://www. R-project.org

Smith S, Stewart N, Gates J (1999) Home ranges, habitat selection and mortality of ring-necked pheasants (Phasianus colchicus) in North-central Maryland. Am Midl Nat 141:185-197

Tufto J, Cavallini P (2005) Should wildlife biologists use free software? Wildlife Biol 11:67-76

Venturato E, Cavallini P, Banti P, Dessì-Fulgheri F (2009) Do radiocollars influence mortality and reproduction? A case with ringnecked pheasants (Phasianus colchicus) in Central Italy. European Journal of Wildlife Research. doi:10.1007/s10344-009-0271-6

White GC, Garrott RA (1990) Analysis of wildlife radio-tracking data. Academic, San Diego 